\title{
Validation of the Mood and Anxiety Symptom Questionnaire in Korean Adolescents
}

\author{
Seul-Ah Lee ${ }^{1}$, Keun-Hyang $\mathrm{Kim}^{2}{ }^{凶}$, and Sun-Mi $\mathrm{Cho}^{3 凶}$ \\ ${ }^{1}$ Ajou Psychological Counseling Center, Suwon, Republic of Korea \\ ${ }^{2}$ Department of Psychology, Daegu University, Gyeongsan, Republic of Korea \\ ${ }^{3}$ Department of Psychiatry \& Behavioral Science, Ajou University School of Medicine, Suwon, Republic of Korea
}

\begin{abstract}
Objective The tripartite model categorizes symptoms of depression and anxiety into three groups: 1) non-specific general distress that is shared between depression and anxiety, 2) depression-specific symptoms that include low positive affect and loss of interest, and 3) anxiety-specific symptoms that include somatic arousal. The Mood and Anxiety Symptoms Questionnaire (MASQ) was developed to measure these three factors of depression and anxiety. The purpose of the present study was to test the psychometric properties of the Korean version of the MASQ (K-MASQ) in adolescents.

Methods Community-dwelling adolescents $(\mathrm{n}=933)$ were randomly assigned to two groups. Exploratory factor analysis and confirmatory factor analysis were conducted in each group to identify the factor structure of the K-MASQ. The reliability and validity of the K-MASQ were also evaluated.

Results Our results support the three-factor structure of the K-MASQ in adolescents. However, we found that the specific items of each factor differed from those of the original MASQ. That is, the depression-specific factor was only related to low positive affect and not loss of interest, and the anxiety-specific factor included more items related to general somatic symptoms of anxiety. The reliability and validity of the K-MASQ were found to be satisfactory.

Conclusion The K-MASQ supports the tripartite model of depression and anxiety and has satisfactory reliability and validity among Korean adolescents. The K-MASQ can be used to distinguish unique symptoms of depression and anxiety in Korean adolescents.
\end{abstract}

Psychiatry Investig 2015;12(2):218-226

Key Words Anxiety, Depression, Assessment, Adolescent, Mood and Anxiety Symptom Questionnaire, Korea.

\section{INTRODUCTION}

Depression and anxiety are the most common mood states in both clinical and non-clinical settings and symptoms of depression and anxiety often co-occur. Several previous studies show that measures of anxiety and depression are highly correlated and often not clearly differentiated. Watson and Kendall report that because the two states share similar symptoms, they are difficult to distinguish using existing self-report

Received: January 19, 2014 Revised: March 26, 2014

Accepted: April 11, 2014 Available online: December 12, 2014

$\triangle$ Correspondence: Keun-Hyang Kim, PhD

Department of Psychology, Daegu University, 201 Daegu-daero, Gyeongsan 712-714, Republic of Korea

Tel: +82-53-850-6360, Fax: +82-53-850-6369, E-mail: kh.kim@daegu.ac.kr

$\triangle$ Correspondence: Sun-Mi Cho, $\mathrm{PhD}$

Department of Psychiatry \& Behavioral Science, Ajou University School of Medicine, 164 Worldcup-ro, Yeongtong-gu, Suwon 443-380, Republic of Korea Tel: +82-31-219-5180, Fax: +82-31-219-5179, E-mail: smcho@ajou.ac.kr

(a) This is an Open Access article distributed under the terms of the Creative Commons Attribution Non-Commercial License (http://creativecommons.org/licenses/bync/3.0) which permits unrestricted non-commercial use, distribution, and reproduction in any medium, provided the original work is properly cited. inventories. ${ }^{1,2}$ As most anxiety or depression scales are highly correlated, they tend to assess general distress resulting from either depression or anxiety rather than a single state. In addition, the high comorbidity between depression and anxiety has led to the notion that diagnosis of mixed anxiety-depressive disorder should be included in the Diagnostic and Statistical Manual of Mental Disorders. ${ }^{3}$ Although it seems clear that symptoms of depression and anxiety overlap, there are unique symptoms of each mood state. Clark and Watson suggest a tripartite model ${ }^{3}$ in which symptoms of depression and anxiety are categorized into three groups. Specifically, they posit that general distress is a nonspecific state shared by depression and anxiety and is similar to the negative affect factor in the traditional two-factor model. However, low positive affect and loss of interest are more specific to depression than other symptoms such as depressed mood. Furthermore, automatic arousal symptoms such as trembling, shortness of breath, and palpitation are relatively specific to anxiety. The majority of studies support such a three-factor model. ${ }^{4-6}$ 
Watson and Clark ${ }^{7}$ developed the Mood and Anxiety Symptom Questionnaire (MASQ) for directly testing the tripartite model. The MASQ consists of 90 items, with each item scored on a 5-point Likert scale. The MASQ has three sub-factors: general distress, anhedonic depression, and anxiety arousal. Prior validation studies revealed that a three-factor model has adequate convergent and discriminant validity among samples of college students and normal adults. ${ }^{8,9}$ These results not only support the tripartite model but also lead to an expectation that the MASQ can assess depression- and anxiety-specific symptoms more accurately than existing measurement tools.

However, there have been a few unexpected findings regarding MASQ factors and their items. For instance, general somatic distress associated with anxiety was expected to belong to the general distress factor but instead was shown to be more relevant to the anxiety-specific factor, leading Watson et al. ${ }^{9}$ to propose defining anxiety-specific symptoms as general somatic distress rather than hyperarousal. Bedford also raised a question about the item structure of the MASQ. ${ }^{10}$ That is, when selecting items with a factor loading greater than 0.30 and a major loading 0.20 higher than that of other items, low positive affect but not loss of interest appear relevant to the depression-specific sub-factor. Thus, Bedford suggested that the MASQ can be divided into three sub-factors: general distress, positive affect, and somatic anxiety. The results of Keogh and Reidy's factor analysis also support a three-factor model when removing items with a factor loading of less than 0.30 and cross loading of less than $0.20 .{ }^{5}$ However, items relevant to general somatic symptoms tend to be associated with the anxiety-specific factor, and only low positive affect seems to be linked to the depression-specific factor.

Despite these discrepancies among studies in factor structure, the MASQ is becoming more widely used for assessing depression and anxiety in adolescents and adults. ${ }^{11-13}$ Adolescents go through drastic social, psychological, and biological changes and have emotional experiences distinct from those of children or adults. They also tend to express depression and anxiety differently. For instance, adults are likely to report their depressed mood with direct language, and children have a tendency to show somatic complaints, whereas adolescents are prone to becoming irritable and bored when depressed. ${ }^{14-16}$ Therefore, it is necessary to either develop new measures to assess depression and anxiety in adolescents or to revise existing measures to make them suitable for adolescents. To date, however, it is rare to find a self-report inventory for adolescents with acceptable reliability and validity. The Beck Depression Index and Beck Anxiety Index are two of the most widely used inventories for assessing depression and anxiety in adults, and the Children's Depression Index (CDI) and Revised Children's Manifest Anxiety Scale (RCMAS) were developed for children, but these scale have limited use for adolescents. Moreover, the validity of the MASQ has not been determined for adolescents, and the adequacy of using the same MASQ factor structure for both adults and adolescents has not yet been demonstrated.

In the present study, we first translated the MASQ into the Korean language (K-MASQ) and explored its items and factor structure using a sample of Korean adolescents. Second, we examined the model fit of the extracted factor structure using confirmatory factor analysis. Third, we determined the reliability as well as convergent and discriminant validity of the K-MASQ.

\section{METHODS}

\section{Participants}

Participants were 1117 adolescents aged 12-18 years from nine middle schools and high schools in Seoul, Daejeon, Dae$\mathrm{gu}$, and Gyeonggi Province. Data were collected between January 2012 and June 2012. The purpose and methods of the study were reviewed in advance by school authorities, who confirmed that the possibility of harm was extremely low. All students received an explanation of the study, and every procedure was conducted under the supervision of homeroom teachers. Of the 1117 participants who signed informed consent forms, 184 participants gave identical responses to more than two-thirds (i.e., 60) of the MASQ items; these were regarded as random responses and were excluded from analysis. Thus, 933 participants (429 males, 504 females) who provided complete data were included in the analysis. Participants were randomly assigned to group 1 or group 2. Exploratory factor analysis was conducted in group $1(\mathrm{n}=478 ; 217$ males, 261 females) using PASW 18.0 software, and confirmatory factor analysis was conducted in group $2(\mathrm{n}=455 ; 212$ males, 243 females) using AMOS 8.0 software. Of the 933 participants, 85 were in the first year of middle school, 103 were in the second year of middle school, 125 were in the third year of middle school, 203 were in the first year of high school, 202 were in the second year of high school, and 215 were in the third year of high school at the time of assessment. The mean age of males was 15.29 years [standard deviation $(\mathrm{SD})=1.66$ ], and the mean age of females was 15.38 years $(\mathrm{SD}=1.61)$.

\section{Measures}

\section{Korean-Mood and Anxiety Symptom Questionnaire}

The MASQ was developed to assess similarities and differences between anxiety and depressive symptoms. ${ }^{7}$ Each item is scored on a Likert scale ranging from 1 to 5 . The original version of the MASQ consists of 90 items and six sub-factors 
based on the tripartite model. However, positive affect and loss of interest sub-factors were combined into a sub-factor of anhedonic depression after some items with doubtful validity were excluded. The anhedonic depression sub-factor consists of 14 reverse-keyed items related to positive affect and eight items related to loss of interest. Also, Watson et al. ${ }^{8}$ suggested combining three subscales of general distress, which consists of 38 items, into one subscale. The anxiety arousal sub-factor consists of 17 items related to somatic tension and hyperarousal. In the present study, we adopted three subscales of the MASQ, which we compared to our factor analysis results. Also, as we aimed to explore the factor structure of the original version of the MASQ, we thus included all 90 items for analysis. The MASQ was translated into the Korean language by two clinical psychologists, after which back-translation was performed by a person who was bilingual in English and Korean. After resolving minimal discrepancies, the final version of the KMASQ was completed.

\section{Children's Depression Inventory}

The CDI is a 27-item self-report questionnaire designed to assess various symptoms of depression in children. ${ }^{17}$ Each item consists of three statements and is scored 0,1 , or 2 , resulting in total scores ranging from 0 to 54 . A higher CDI score indicates greater depressive symptoms. The Korean version of the $\mathrm{CDI}^{18}$ has a Cronbach's $\alpha$ of 0.85 . Because the Korean version of the CDI shows acceptable reliability and validityi and has been used in many prior studies to measure the symptoms of depression in Korean adolescents, it was used for this study. ${ }^{19,20}$ Factor analysis of the CDI revealed that a four-factor model (negative emotion/somatic symptoms, ineffectiveness, interpersonal problems, and externalizing problems) is adequate in adolescents. ${ }^{21}$ Total CDI scores and sub-factor scores were included in our analysis.

\section{Revised Children's Manifest Anxiety Scale}

The CMAS was developed by Castenada and colleagues and revised by Reynolds and Richmond. ${ }^{22,23}$ The RCMAS is a 37-item self-report instrument designed to assess anxiety in children and adolescents. The RCMAS consists of 28 anxiety items and 9 lie (i.e., social desirability) items with either "yes" or "no" responses. The Korean version of the RCMAS has a Cronbach's $\alpha$ of $0.87 .{ }^{24}$ In many studies of Korean adolescents, the RCMAS has been used to measure anxiety symptoms..$^{25,26}$ Four RCMAS sub-factors, identified by a previous study, ${ }^{27}$ were included in our analysis: excessive worry, oversensitivity, physiological symptoms/sleep disturbance, and low self-esteem/ anhedonia.

\section{Statistical analysis}

Exploratory factor analysis using PASW 18.0 were conducted in group 1 to explore the factor structure of the KMASQ. Principal axis factoring was performed, and Promax rotation (kappa $=4)$, an oblique rotation technique, was carried out. Confirmatory factor analysis using AMOS 8.0 was performed in group 2 to determine the adequacy of the model from the exploratory factor analysis. Cronbach's a was calculated to evaluate the internal reliability of the K-MASQ. Correlation analyses of the K-MASQ and other depression and anxiety scales were also performed to determine convergent and discriminant validity.

\section{RESULTS}

\section{Factor analysis of the Korean-Mood and Anxiety Symptom Questionnaire for adolescents}

\section{Exploratory factor snalysis}

The first step in the analysis was to determine how many meaningful factors should be retained. Exploratory factor analysis was performed using PASW 18.0. When principal axis factoring was conducted without entering the number of factors, there were eight factors with eigenvalues greater than 1. From the third factor onward, however, there were only minor differences in eigenvalues (eigenvalue differences being $19.726,9.577,3.572,2.104,2.031,1.960$, etc.). In consideration of the minor differences in eigenvalues, we specified the number of factors and then attempted to find the most appropriate factor structure. Total variance explained was higher when three factors were entered compared with two factors. This finding of the adequacy of a three-factor model is consistent with prior research. ${ }^{3,7,8}$ Several items with a factor loading of less than 0.3 or for which the difference between factor loadings was less than 0.2 were excluded according to Bedford's suggestion. ${ }^{10}$ The final 76 items and factor loadings are presented Table 1.

The items associated with each factor seemed more consistent with the results of Keogh and Reidy ${ }^{5}$ rather than those of Watson and Clark. ${ }^{7}$ Factor 1 consisted of several items from the general distress scale of Watson and Clark, suggesting that this factor is most relevant to general distress. However, a few loss of interest items from the anhedonic depression scale were also included in Factor 1 (e.g., "Felt like it took extra effort to get started", "Felt withdrawn from other people"). Thus, our general distress factor included both loss of interest and emotional distress items such as worry, concern, and depression. Factor 2 consisted of items from the anhedonic depression scale. Clark and Watson ${ }^{3}$ argued that their anhedonic depression scale includes low positive affect and loss of inter- 
SA Lee et al.

Table 1. Promax-rotated factor loadings of the MASQ items

\begin{tabular}{|c|c|c|c|c|c|}
\hline & Items & General distress & Positive affect & Somatic anxiety & Original MASQ \\
\hline 84 & Worried a lot about things & 0.794 & -0.023 & -0.173 & 1 \\
\hline 74 & Was disappointed in myself & 0.762 & -0.007 & -0.083 & 1 \\
\hline 15 & Felt nervous & 0.749 & 0.137 & -0.065 & 1 \\
\hline 29 & Felt dissatisfied with everything & 0.712 & -0.118 & -0.083 & 1 \\
\hline 16 & Felt depressed & 0.707 & -0.106 & -0.029 & 1 \\
\hline 4 & Felt confused & 0.686 & -0.013 & -0.026 & 1 \\
\hline 39 & Felt like it took extra effort to get started & 0.672 & 0.402 & -0.258 & 2 \\
\hline 76 & Had trouble concentrating & 0.654 & -0.015 & -0.105 & 1 \\
\hline 64 & Felt inferior to others & 0.629 & 0.078 & -0.061 & 1 \\
\hline 70 & Had trouble making decisions & 0.627 & 0.152 & -0.063 & 1 \\
\hline 8 & Felt discouraged & 0.623 & 0.004 & 0.056 & 1 \\
\hline 26 & Felt withdrawn from other people & 0.618 & -0.001 & 0.058 & 2 \\
\hline 24 & Blamed myself for a lot of things & 0.618 & 0.087 & 0.092 & 1 \\
\hline 6 & Felt sad & 0.614 & 0.046 & 0.004 & 1 \\
\hline 80 & Had trouble paying attention & 0.614 & 0.145 & -0.012 & 1 \\
\hline 2 & Felt afraid & 0.597 & -0.019 & -0.003 & 1 \\
\hline 13 & Felt worthless & 0.591 & -0.115 & 0.072 & 1 \\
\hline 10 & Felt like crying & 0.581 & -0.026 & 0.053 & 1 \\
\hline 17 & Felt irritable & 0.567 & -0.083 & -0.005 & 1 \\
\hline 82 & Felt keyed up, "on edge" & 0.562 & 0.012 & 0.187 & 1 \\
\hline 20 & Felt uneasy & 0.548 & -0.079 & 0.135 & 1 \\
\hline 22 & Felt hopeless & 0.548 & -0.206 & 0.118 & 1 \\
\hline 28 & Was afraid I was going to lose control & 0.543 & 0.062 & 0.116 & us \\
\hline 53 & Felt unattractive & 0.529 & -0.093 & 0.029 & 2 \\
\hline 90 & Got tired or fatigued easily & 0.523 & -0.006 & 0.119 & 1 \\
\hline 47 & Felt like a failure & 0.522 & -0.150 & 0.134 & 1 \\
\hline 77 & Felt tense or "high-strung" & 0.521 & 0.184 & 0.130 & 1 \\
\hline 33 & Felt like nothing was very enjoyable & 0.517 & -0.310 & 0.088 & 2 \\
\hline 50 & Felt very restless & 0.514 & -0.003 & 0.251 & 1 \\
\hline 56 & Felt very clearheaded & 0.473 & 0.059 & 0.154 & 1 \\
\hline 42 & Felt pessimistic about the future & 0.456 & -0.179 & 0.033 & 1 \\
\hline 60 & Felt like being by myself & 0.440 & -0.081 & 0.062 & us \\
\hline 34 & Felt like something awful was going to happen & 0.433 & -0.112 & 0.209 & 1 \\
\hline 58 & Felt really "up" or lively & -0.032 & 0.759 & 0.028 & 2 \\
\hline 40 & Felt like I had a lot to look forward to & 0.231 & 0.747 & -0.097 & 2 \\
\hline 86 & Felt really good about myself & -0.016 & 0.719 & -0.042 & 2 \\
\hline 36 & Felt like I had accomplished a lot & -0.048 & 0.711 & -0.017 & 2 \\
\hline 68 & Felt confident about myself & 0.020 & 0.702 & -0.072 & us \\
\hline 30 & Looked forward to things with enjoyment & 0.045 & 0.691 & -0.003 & 2 \\
\hline 72 & Felt like I had a lot of energy & -0.090 & 0.686 & -0.032 & 2 \\
\hline 23 & Felt like I was having a lot of fun & -0.139 & 0.665 & 0.008 & 2 \\
\hline 14 & Felt really happy & -0.151 & 0.660 & 0.035 & 2 \\
\hline 78 & Felt hopeful about the future & -0.017 & 0.658 & 0.024 & 2 \\
\hline 49 & Was proud of myself & -0.076 & 0.624 & 0.149 & 2 \\
\hline
\end{tabular}


Table 1. Promax-rotated factor loadings of the MASQ items (continued)

\begin{tabular}{|c|c|c|c|c|c|}
\hline & Items & General distress & Positive affect & Somatic anxiety & Original MASQ \\
\hline 62 & Was able to laugh easily & 0.076 & 0.588 & -0.105 & us \\
\hline 1 & Felt cheerful & -0.087 & 0.573 & -0.061 & 2 \\
\hline 35 & Felt like I accomplished a lot & -0.116 & 0.560 & 0.189 & 2 \\
\hline 38 & Felt like being with other people & 0.380 & 0.559 & -0.184 & us \\
\hline 43 & Felt like I could do everything I needed to do & 0.009 & 0.558 & 0.095 & us \\
\hline 11 & Felt successful & -0.126 & 0.503 & 0.195 & us \\
\hline 27 & Seemed to move quickly and easily & -0.090 & 0.495 & 0.126 & 2 \\
\hline 46 & Felt really talkative & 0.232 & 0.492 & -0.011 & us \\
\hline 41 & Thoughts and ideas came to me very easily & -0.067 & 0.471 & 0.154 & us \\
\hline 18 & Felt optimistic & 0.104 & 0.418 & 0.030 & 2 \\
\hline 79 & Was trembling or shaking & -0.031 & 0.058 & 0.697 & 3 \\
\hline 55 & Was short of breath & -0.104 & -0.024 & 0.623 & 3 \\
\hline 81 & Muscles were tense or sore & 0.042 & 0.057 & 0.609 & 3 \\
\hline 87 & Had trouble swallowing & -0.170 & 0.015 & 0.582 & 3 \\
\hline 61 & Felt like I was choking & -0.087 & -0.075 & 0.581 & 3 \\
\hline 9 & Felt nauseous & 0.047 & -0.048 & 0.543 & 1 \\
\hline 57 & Hands were shaky & 0.036 & -0.063 & 0.512 & 3 \\
\hline 65 & Had a lump in my throat & 0.006 & 0.119 & 0.506 & 1 \\
\hline 48 & Had hot or cold spells & 0.029 & 0.089 & 0.500 & 3 \\
\hline 19 & Felt faint & 0.041 & -0.015 & 0.490 & 3 \\
\hline 45 & Had pain in my chest & 0.018 & -0.031 & 0.488 & 3 \\
\hline 83 & Had trouble staying asleep & 0.057 & 0.022 & 0.479 & 1 \\
\hline 63 & Had an upset stomach & 0.127 & -0.025 & 0.472 & 1 \\
\hline 75 & Heart was racing or pounding & 0.197 & 0.223 & 0.465 & 3 \\
\hline 52 & Felt dizzy or lightheaded & 0.162 & 0.024 & 0.461 & 3 \\
\hline 25 & Felt withdrawn from other people & 0.021 & 0.009 & 0.459 & 3 \\
\hline 37 & Did not have much of an appetite & -0.033 & -0.066 & 0.451 & 1 \\
\hline 66 & Felt really slowed down & 0.151 & 0.064 & 0.435 & 2 \\
\hline 69 & Muscles twitched or trembled & 0.183 & 0.096 & 0.393 & 3 \\
\hline 88 & Hands were cold or sweaty & 0.069 & 0.091 & 0.362 & 3 \\
\hline 51 & Had trouble falling asleep & 0.122 & 0.025 & 0.355 & 1 \\
\hline \multirow[t]{4}{*}{12} & Had diarrhea & -0.008 & 0.055 & 0.317 & 1 \\
\hline & Eigenvalue & 17.484 & 8.783 & 3.512 & \\
\hline & Variance per Factor (\%) & 23.005 & 11.556 & 4.621 & \\
\hline & Total Variance (\%) & & 39.182 & & \\
\hline
\end{tabular}

1: general distress, 2: anhedonic depression, 3: anxiety arousal. us: unspecified, MASQ: Mood and Anxiety Symptom Questionnaire

est items. However, our Factor 2 consisted of only one positive affect item, consistent with the results of Bedford ${ }^{10}$ and Keogh and Reidy. ${ }^{5}$ Factor 3 consisted mainly of items from the anxiety arousal scale, which is thought to reflect hyperarousal. However, Factor 3 also contained somatic symptomrelated items from the general distress scale, sleep disturbanceand loss of appetite-related items, and "Felt really slowed down" from the anhedonic depression scale. These somatic symptoms seem more homogeneous with somatic arousal items than items from the general distress or anhedonic depression scales. Therefore, we labeled Factor 1 as 'general distress', Factor 2 as 'positive affect', and Factor 3 as 'somatic anxiety', consistent with previous studies. ${ }^{5,10}$

\section{Confirmatory factor analysis}

Structural equation modeling was performed to examine 
the goodness of fit of a three-factor model using Maximum Likelihood Method in AMOS 8.0. Model fit was assessed using a series of fit indices: Root Mean Square Error of Approximation (RMSEA), Tucker-Lewis Index (TLI), and Comparative Fit Index (CFI). The RMSEA is not sensitive to sample size and reflects the simplicity of the model. Although the TLI and CFI do not reflect the simplicity of the model, they are robust to sample size. An RMSEA less than 0.05 and TLI and CFI greater than 0.90 indicate good model fit. The results of our confirmatory factor analysis are presented in Table 2 . We found an RMSEA of 0.043 , TLI of 0.851 , and CFI of 0.861 . Thus, a three-factor model for the K-MASQ in adolescents was considered appropriate.

\section{Reliability}

\section{Internal consistency}

Cronbach's $\alpha$ for the entire K-MASQ scale for adolescents was 0.94 . For the three-factor model, Cronbach's a for general distress, positive affect, and somatic anxiety factors were $0.95,0.92$, and 0.88 , respectively.

\section{Validity}

Pearson's correlation analyses were conducted to explore the relationships between the K-MASQ, CDI, and RCMAS.
The results are presented in Table 3. For the K-MASQ, the general distress factor was strongly correlated with the somatic anxiety factor $(\mathrm{r}=0.62, \mathrm{p}<0.001)$ but weakly correlated with the positive affect factor $(\mathrm{r}=-0.23, \mathrm{p}<0.001)$. No significant correlation was found between the somatic anxiety and positive affect factors. These results are somewhat different than those of prior studies in adults, which report relatively strong correlations between the general distress factor and the somatic anxiety and positive affect factors and modest correlations between the somatic anxiety and positive affect factors. ${ }^{5,9}$ In addition, the K-MASQ general distress factor was modestly to strongly correlated with total scores and all sub-factors of the CDI and RCMAS. This result indicates that the KMASQ general distress factor adequately assesses general negative affect, including both depression and anxiety. The K-MASQ positive affect factor showed a relatively strong correlation with the CDI, which measures depression, but a weak correlation with the RCMAS, which measures anxiety. In particular, the negative emotion/somatic symptoms factor of the CDI was strongly associated with K-MASQ general distress and somatic anxiety factors, whereas the ineffectiveness and interpersonal problems factors of the CDI were strongly associated with the K-MASQ positive affect factor. Our results indicate that low positive affect could be regarded as a depression-specific factor in adolescents and is particu-

Table 2. Goodness-of-fit Indices for K-MASQ model ( $\mathrm{N}=455)$

\begin{tabular}{ccccccc}
\hline Goodness-of-fit index & $\chi^{2}(\mathrm{p})$ & $\mathrm{df}$ & CMIN/DF & RMSEA & TLI & CFI \\
\hline K-MASQ 76 items & $4898.43(0.000)$ & 2663 & 1.839 & 0.043 & 0.851 & 0.861 \\
\hline
\end{tabular}

K-MASQ: Korean version of the Mood and Anxiety Symptom Questionnaire, RMSEA: Root Mean Square Error of Approximation, TLI: Tucker-Lewis Index, CFI: Comparative Fit Index

Table 3. Relations among K-MASQ, CDI, and RCMAS (N=926)

\begin{tabular}{|c|c|c|c|c|}
\hline Measures & MASQ_GD & MASQ_PA & MASQ_SA & MASQ_total \\
\hline MASQ_general distress & - & $-0.23^{* *}$ & $0.62^{* *}$ & $0.92^{* *}$ \\
\hline MASQ_positive affect & $-0.23^{* *}$ & - & 0.02 & $-0.52^{* *}$ \\
\hline MASQ_somatic anxiety & $0.62^{* *}$ & 0.02 & - & $0.69 * *$ \\
\hline MASQ_total & $0.92^{* *}$ & $-0.52^{* *}$ & $0.69 * *$ & - \\
\hline CDI_total & $0.64^{* *}$ & $-0.48^{* *}$ & $0.45^{* *}$ & $0.73^{* *}$ \\
\hline RCMAS_total & $0.63^{* *}$ & $-0.24^{* *}$ & $0.46^{* *}$ & $0.64^{* *}$ \\
\hline CDI_negative emotion/somatic symptoms & $0.61^{* *}$ & $-0.32^{* *}$ & $0.53^{* *}$ & $0.67^{* *}$ \\
\hline CDI_ineffectiveness & $0.48^{* *}$ & $-0.41^{* *}$ & $0.26^{* *}$ & $0.54^{* *}$ \\
\hline CDI_interpersonal problems & $0.53^{* *}$ & $-0.52^{* *}$ & $0.30^{* *}$ & $0.63^{* *}$ \\
\hline CDI_externalizing problem & $0.20 * *$ & $-0.18^{* *}$ & $0.22 * *$ & $0.27^{* *}$ \\
\hline RCMAS_excessive worry & $0.57^{* *}$ & $-0.18^{* *}$ & $0.35^{* *}$ & $0.54^{* *}$ \\
\hline RCMAS_oversensitivity & $0.45^{* *}$ & $-0.15^{* *}$ & $0.29^{* *}$ & $0.43^{* *}$ \\
\hline RCMAS_somatic symptoms/sleep disturbance & $0.37^{* *}$ & $-0.12^{* *}$ & $0.47^{* *}$ & $0.42^{* *}$ \\
\hline RCMAS_low self-esteem/feeling of unhappiness & $0.56^{* *}$ & $-0.26^{* *}$ & $0.36^{* *}$ & $0.57^{* *}$ \\
\hline
\end{tabular}

${ }^{* *} \mathrm{p}<0.001$. CDI: Children's Depression Index, RCMAS: Revised Children's Manifest Anxiety Scale, K-MASQ: Korean version of the Mood and Anxiety Symptom Questionnaire 
larly linked to self-efficacy and interpersonal functioning. On the other hand, the somatic anxiety factor showed moderate positive correlations with both the CDI and RCMAS. In particular, the somatic anxiety factor was strongly associated with the negative emotion/somatic symptoms factor of the CDI and the somatic symptoms/sleep disturbance factor of the RCMAS.

\section{DISCUSSION}

In this study, we translated the MASQ, which is designed to measure depression and anxiety based on the tripartite model, into the Korean language and explored its factor structure for adolescents. We also verified its reliability and validity. Our factor analysis revealed that a three-factor model was adequate for the K-MASQ, which is consistent with several previous studies. However, some findings regarding sub-factor items were not consistent with prior results. ${ }^{89}$ The presence of the general distress factor that measures common aspects of anxiety and depression was not dissimilar from that of Clark and Watson. ${ }^{3}$ However, the anxiety-specific factor contained general somatic distress items such as fatigue and insomnia as well as hyperarousal-related items. In addition, although Clark and Watson proposed that the depression-specific factor consists of both low positive affect and loss of interest items, it consisted of only low positive affect items in the present study.

Although the anxiety-specific factor still contained all of the automatic arousal-related items, it resembled a somatic anxiety factor that includes items related to general somatic symptoms of anxiety. These results are consistent with previous factor analysis studies in adult samples. ${ }^{5,8}$ However, in our study, the "Felt really slowed down" item, which is linked with loss of interest, was included in the somatic anxiety factor. Considering adolescents' developmental features, their perception of their body and emotions might not be as differentiated as those in adults. Therefore, it is possible that more items relevant to general somatic symptoms were included in our study than in previous studies with adults.

We also found that the depression-specific factor only contained low positive affect-related items, whereas loss of interest items were included in the general distress factor, which is not consistent with Clark and Watson's model. ${ }^{3}$ However, our results are similar to those of other studies ${ }^{5,28}$ that also excluded several items with factor loadings of less than 0.30 or a difference between factor loadings of less than 0.20. When Keogh and Reidy ${ }^{5}$ analyzed Watson and colleagues' factor loadings, ${ }^{8}$ positive affect-related items seemed dominant in the depression-related dimension. Considering the results of prior research and our study, the depression-specific factor seem more clearly linked to low positive affect rather than loss of interest.

We also examined relationships among the K-MASQ, CDI, and RCMAS to verify convergent validity and discriminant validity. We found a significant correlation $(\mathrm{r}=0.62)$ between the general distress and somatic anxiety factors, but a weak correlation was observed between the general distress and positive affect factors $(r=-0.23)$. These results are different from those of prior studies of the MASQ in adults, which showed correlations ranging between 0.50 and $0.60 .{ }^{5.9}$ However, the positive affect factor was correlated more strongly $(\mathrm{r}=-0.48)$ with the CDI than the RCMAS ( $r=-0.24)$, indicating a reliable depression-specific scale. One possible explanation of these results is the emotional features of adolescents. Adolescents have distinctive emotional characteristics compared to adults; they tend to experience both positive and negative emotions more extremely, react to external and internal emotional cues more strongly, and have more frequent emotional fluctuations even within a day. ${ }^{29-32}$ Thus, it is likely that adolescents' mood states assessed by the MASQ during one week might be more inconsistent than those of adults. As a result, adolescents may show a smaller inverse correlation between negative affect and positive affect. On the other hand, the general distress and positive affect factors showed strong correlations with the CDI. As general distress is linked to negative mood state, and positive affect is linked to academic/interpersonal adaptation, those two factors could reflect different aspects of depression.

The somatic anxiety factor was correlated with the CDI $(\mathrm{r}=0.45)$ and the RCMAS $(\mathrm{r}=0.46)$. In particular, the somatic anxiety factor showed a strong association with RCMAS somatic symptoms/sleep disturbance, which is consistent with an assumption that somatic anxiety reflects somatic symptoms among various anxiety states. However, a strong association was also observed between somatic anxiety and CDI negative emotion/somatic symptoms. This could be because the somatic anxiety factor contained several items related to fatigue, sleep problems, and loss of appetite. These results suggest that although the somatic anxiety factor predominately contained anxiety-related somatic symptoms, it also included some general somatic symptoms due to adolescents' developmental features. Thus, it is possible that high scores on the somatic anxiety factor might be observed when a respondent experiences depression-related somatic distress.

Our results show that the internal consistency of the KMASQ in adolescents was 0.94, which is high, and the internal consistencies for the general distress, positive affect, and somatic anxiety factors were $0.95,0.92$, and 0.88 , respectively, which is good. These results suggest that the K-MASQ is a reliable scale to assess depression and anxiety in adolescents, and the general distress, positive affect, and somatic anxiety 
sub-factors can be used separately.

An additional analysis was conducted to identify differences in MASQ scores between middle school and high school students and between males and females. The results show that MASQ scores of high school students were significantly higher than those of middle school students, and MASQ scores in females were significantly higher than those in males [middle school students: mean $(\mathrm{M})=180.25, \mathrm{SD}=37.75$; high school students: $\mathrm{M}=190.19, \mathrm{SD}=40.01 ; \mathrm{F}=12.28, \mathrm{p}<0.01$; males: $\mathrm{M}=181.74$, $\mathrm{SD}=37.78$; females: $\mathrm{M}=191.20, \mathrm{SD}=40.49 ; \mathrm{F}=9.41$, $\mathrm{p}<0.01]$. This study aimed to determine the factor structure of the K-MASQ among Korean adolescents and to verify the scale's reliability and validity. Thus, differences in MASQ scores according to age and gender should be examined in detail in further studies. In addition, the adequacy of the factor structure could be weaker when mean differences are not considered in the analysis of the correlation matrix. ${ }^{33}$ Therefore, statistical techniques reflecting differences between age and gender should be used in future studies.

We explored a three-factor model of the MASQ among Korean adolescents and tested its reliability and validity. Our results revealed a three-factor structure, but some items within sub-factors were somewhat different from those of the original MASQ. Therefore, when the MASQ is used for adolescents, these configurations of sub-factors should be considered in its administration and interpretation. The validity and reliability of the sub-factors were satisfactory, which makes it possible to use sub-factors separately. This would help in understanding respondents' patterns of depression and anxiety depending on the patterns of each sub-factor. However, the discriminant validity of the anxiety-specific factor was somewhat weak, which should be verified in future studies. As we only included a community population in our study, it is essential to examine response patterns of the K-MASQ in a clinical sample in further research.

\section{Acknowledgments}

We obtained permission for this research from David Watson, the original author of the MASQ.

\section{REFERENCES}

1. Watson D, Kendall PC. Common and Differentiating Features of Anxiety and Depression: Current Findings and Future Directions. In: Kendall PC, Watson D, Editors. Anxiety and Depression: Distinctive and Overlapping Features. London: Academic, 1989, p.493-508.

2. Watson D, Kendall, PC. Understanding Anxiety and Depression: Their Relation to Negative and Positive Affective States. In: Kendall PC, Watson D, Editors. Anxiety and Depression: Distinctive and Overlapping Features. London: Academic, 1989, p.3-26.

3. Clark LA, Watson D. Tripartite model of anxiety and depression: psychometric evidence and taxonomic implications. J Abnorm Psychol 1991;100:316-336.

4. Joiner TE Jr, Steer RA, Beck AT, Schmidt NB, Rudd MD, Catanzaro SJ.
Physiological hyperarousal: construct validity of a central aspect of the tripartite model of depression and anxiety. J Abnorm Psychol 1999; 108:290-298.

5. Keogh E, Reidy J. Exploring the factor structure of the mood and anxiety symptom questionnaire (MASQ). J Pers Assess 2000;74:106-125.

6. Marshall GN, Sherbourne CD, Meredith LS, Camp P, Hays RD. The tripartite model of anxiety and depression: Symptom structure in depressive and hypertensive patient groups. J Pers Assess 2003;80:139153.

7. Watson D, Clark LA. The Mood and Anxiety Symptoms Questionnaire (MASQ). Unpublished Manuscript. Iowa: Department of Psychology, University of Iowa; 1991.

8. Watson D, Weber K, Assenheimer JS, Clark LA, Strauss ME, McCormick RA. Testing a tripartite model: I. Evaluating the convergent and discriminant validity of anxiety and depression symptom scales. J Abnorm Psychol 1995;104:3-14.

9. Watson D, Clark LA, Weber K, Assenheimer JS, Strauss ME, McCormick RA. Testing a tripartite model: II. Exploring the symptom structure of anxiety and depression in student, adult, and patient samples. J Abnorm Psychol 1995;104:15-25.

10. Bedford A. On Clark-Watson's tripartite model of anxiety and depression. Psychol Rep 1997;80:125-126.

11. Lumley MN, Harkness KL. Early maladaptive schemas, and symptom profiles in adolescent depression. Cog Ther Res 2007;31:639-657.

12. Hankin BL. Cognitive vulnerability-stress model of depression during adolescence: investigating depressive symptom specificity in a multiwave prospective study. J Abnorm Child Psychol 2008;36:999-1014.

13. Heinza AJ, Kassela JD, Berbaumb M, Mermelstein R. Adolescents' expectancies for smoking to regulate affect predict smoking behavior and nicotine dependence over time. Drug Alcohol Depend 2010;111: 128-135.

14. Carlson GA, Kashani JH. Phenomenology of major depression from childhood through adulthood: analysis of three studies. Am J Psychiatry 1998;145:1222-1225.

15. Kovacs M. Presentation and course of major depressive disorder during childhood and later years of the life span. J Am Acad Child Adolesc Psychiatry 1996;35:705-715.

16. Weiss B, Garber J. Developmental differences in the phenomenology of depression. Dev Psychopathol 2003;15:403-430.

17. Kovacs M. The Children's Depression Inventory (CDI). Psychophamacol Bull 1985;21:955-988.

18. Cho SC, Lee YS. Development of the Korean form of the Kovacs' Childeren's Depression Inventory. J Korean Neuropsychiatr Assoc 1990;29: 943-956.

19. Han SH, Park K. The Relationships of attachment, social anxiety and depression of adolescents: focused on the high school student. J Psychother 2005;5;43-61.

20. Yoo JS, Son JW, Nam MS. The effects of a depression intervention and suicide prevention program in adolescents with high risk of suicide. J Korean Acad Community Health Nurs 2010;21;71-81.

21. Kim EK, Yang JW, Chung YS, Hong SD, Kim JH. Factor structure of the Children's Depression Inventory (CDI) in children and adolescents. Korean J Clin Psychol 2005;24:693-707.

22. Castenada A, McCandless BR, Palermo DS. The children's form of the manifest anxiety scale. Child Dev 1956;27:317-326.

23. Reynolds CR, Richmond BO. What I think and feel: a revised measure of children's manifest anxiety. J Abnorm Child Psychol 1978;6:271280.

24. Choi JS, Cho SC. Assessment of anxiety in children: reliability and validity of revised Children's Manifest Anxiety Scale. J Korean Neuropsychiatr Assoc 1990;29:691-702.

25. Ha EH, Oh GJ, Song DH. Psychosocial risk factors for comorbid adolescents with depression and anxiety. Korean J Psychol Gen 2003;22; 127-144.

26. Choi HI, Jeon DI, Jung MH, Hong NR, Kim JJ, Song JE, et al. Suicidal 
behavior and internet use in adolescent depression. Korean J Psychopharmacol 2012;23;65-73.

27. Park HY, Kim JH, Ko HJ, Hong S. Investigating the structure of the Revised Children's Manifest Anxiety Scale. Korean J Clin Psychol 2005; 24:427-437.

28. de Beurs E, den Hollander-Gijsman ME, Helmich S, Zitman FG. The tripartite model for assessing symptoms of anxiety and depression: psychometrics of the Dutch version of the mood and anxiety symptoms questionnaire. Behav Res Ther 2007;45:1609-1617.

29. Larson R, Richards MH. Divergent Realities: The Emotional Lives of Mothers, Fathers, and Adolescents. New York: Basic Books; 1994.
30. Larson R, Lampman-Petraitis C. Daily emotional states as reported by children and adolescents. Child Dev 1989;60:1250-1260.

31. Silk JS, Siegle GJ, Whalen DJ, Ostapenko LJ, Ladouceur CD, Dahl RE. Pubertal changes in emotional information processing: pupillary, behavioral, and subjective evidence during emotional word identification. Dev Psychopathol 2009;21:7-26.

32. Tottenham N, Hare TA, Casey BJ. Behavioral assessment of emotion discrimination, emotion regulation, and cognitive control in childhood, adolescence, and adulthood. Front Psychol 2011;2:39.

33. Kim CT, Lee SY. The effect of group mean differences upon factor analysis. Surv Res 2001;2:109-130. 